\title{
RASMUSSEN'S ANUERYSM MIMICKING AS A FUNGAL BALL
}

Virupaksha H. M1ㅡ. Krishnaprasad², Kudri G. M³ , Irfan ahmed Makandar ${ }^{4}$

\section{HOW TO CITE THIS ARTICLE:}

Virupaksha H. M. Krishnaprasad, Kudri G. M. Irfan ahmed Makandar. "Rasmussen's Anuerysm Mimicking as a Fungal Ball”. Journal of Evolution of Medical and Dental Sciences 2014; Vol. 3, Issue 23, June 09;

Page: 6291-6296, DOI: 10.14260/jemds/2014/2738

ABSTRACT: Hemoptysis is a common post pulmonary tuberculosis complication. It is usually due to bronchial artery involvement. Hemoptysis due to pulmonary artery pseudoaneurysm in a tuberculosis cavity is very rare. Such pseudoaneurysm is called Rasmussen's aneurysms which are commonly seen in upper lobes. We are able to demonstrate a big left lower lobe Rasmussen's aneurysm in a 55 years old diabetic male by CT pulmonary angiogram and it was treated successfully by a wedge resection of involved pulmonary segments.

KEYWORDS: Pseudoaneurysm, Rasmussen's aneurysm, wedge resection.

INTRODUCTION: Pulmonary arterial aneurysms \& pseudo aneurysms are rare in clinical practice. Recognition \& proper management of such a rare entity is very important because of its associated high mortality. ${ }^{1}$ Rasmussen's aneurysm is a pseudo aneurysm of pulmonary artery in a tuberculosis cavity. A pseudo aneurysm is one, which involves focal dilatation of the wall of artery without involvement of all three layers, hence is more prone to rupture and cause life threatening hemoptysis. $^{2}$

It was first described by Fritz Waldemer Rasmussens, a Danish physician in 1868 in patients with pulmonary tuberculosis. ${ }^{3}$ Its exact incidence is not known. ${ }^{4}$ We are reporting a case of 55yrs old diabetic male patient with past history of pulmonary tuberculosis with left lower lobe Rasmussen's aneurysm mimicking as a fungal ball.

CASE REPORT: A 55yrs old male diabetic patient presented to ER with two episodes of hemoptysis of around $100 \mathrm{ml}$ each time. He is a case of past pulmonary tuberculosis treated 4yrs back. On examination patient was hemodynamically stable, impaired note was percussed in the right supra clavicular \& infra clavicular areas \& dull note in the left mammary \& infra axillary areas. On auscultation intensity of breath sounds were diminished on left lower lung fields.

His haemoglobin was $11 \mathrm{gms} / \mathrm{dl} \&$ erythrocyte sedimentation rate was $50 \mathrm{~mm}$ at end of 1 st $\mathrm{hr}$ with normal blood counts and peripheral blood smear. His chest x-ray shows right upper zone fibrosis and left lower zone peripherally situated mass lesion (figure 1). 


\section{CASE REPORT}

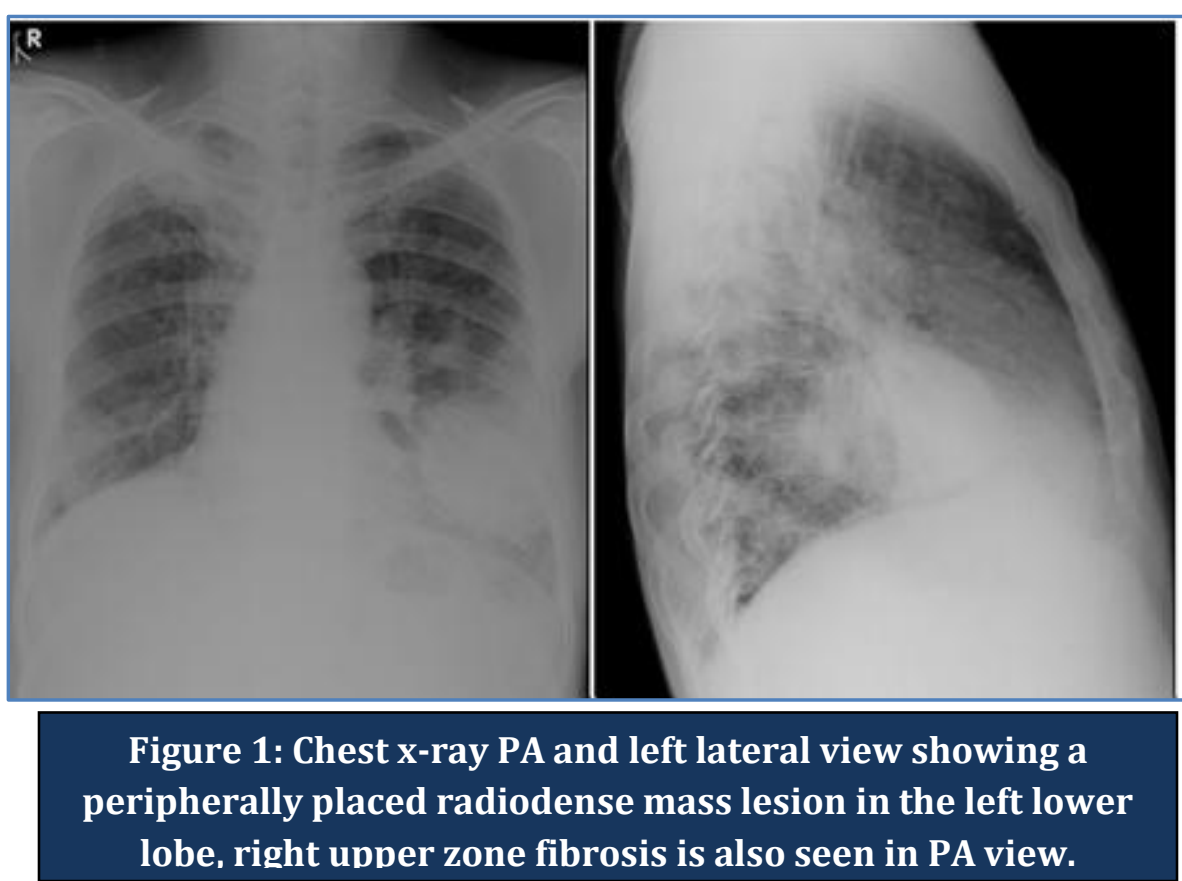

Patient was treated for hemoptysis \& there were no further episodes of hemoptysis. A Plain CT scan of the thorax revealed right upper lobe \& a left lower lobe air crescent sign; there was shift in air crescent with change in patient position (figure 2).

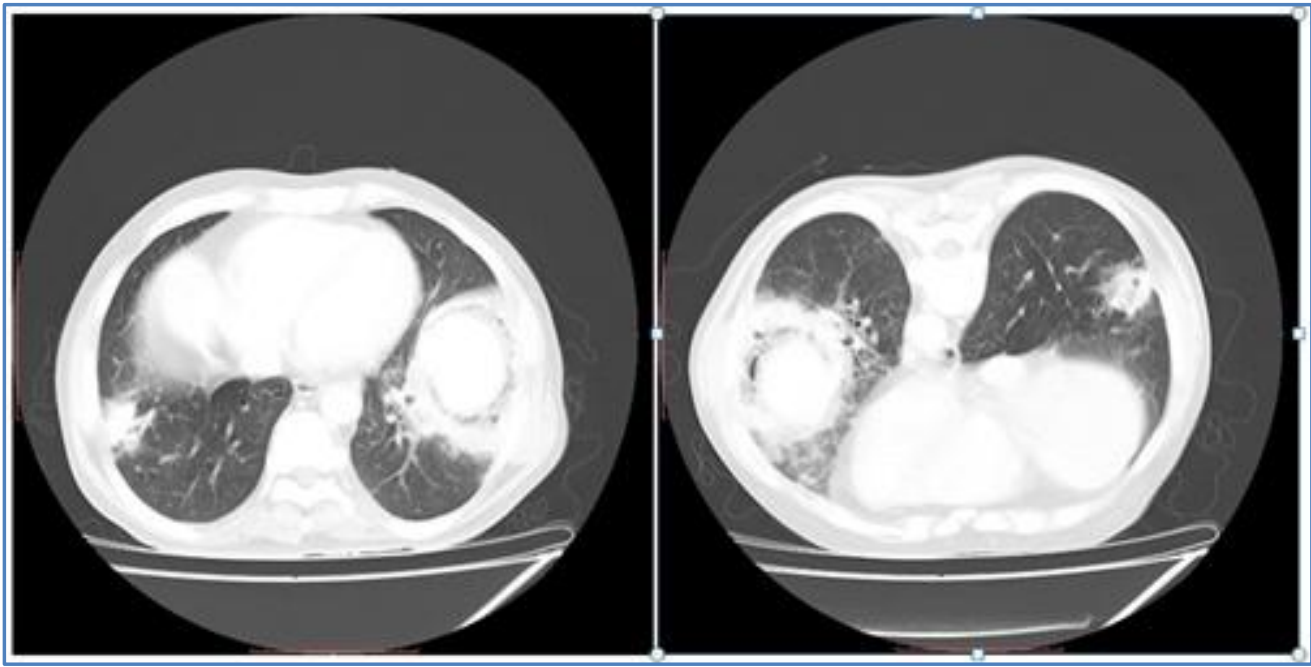

Figure 2: Plain CT thorax showing a well circumscribed intracavitary mass in left lower lobe with air crescent sign, Shift in air crescent is noticed with change in position of patient.

A CECT scan of the thorax revealed right upper lobe mycetoma \& a left lower lobe intra cavitary well circumscribed radio enhancing lesion arising from the wall of cavity suggestive of Rasmussens aneurysms (figure 3). A bronchial artery angiogram showed hypertrophied bronchial arteries in the right upper lobe with no bleeders \& on the left side it was normal. A CT pulmonary 


\section{CASE REPORT}

angiogram was performed \& a branch of left pulmonary artery feeding the intracavitatory lesion of the left lower lobe was demonstrated confirming Rasmussens Aneurysm (figure 3). Surgery was performed, a wedge dissection of left lower lobe pulmonary segments with cavity containing the lesion was resected and cut and sutured (figure 4).

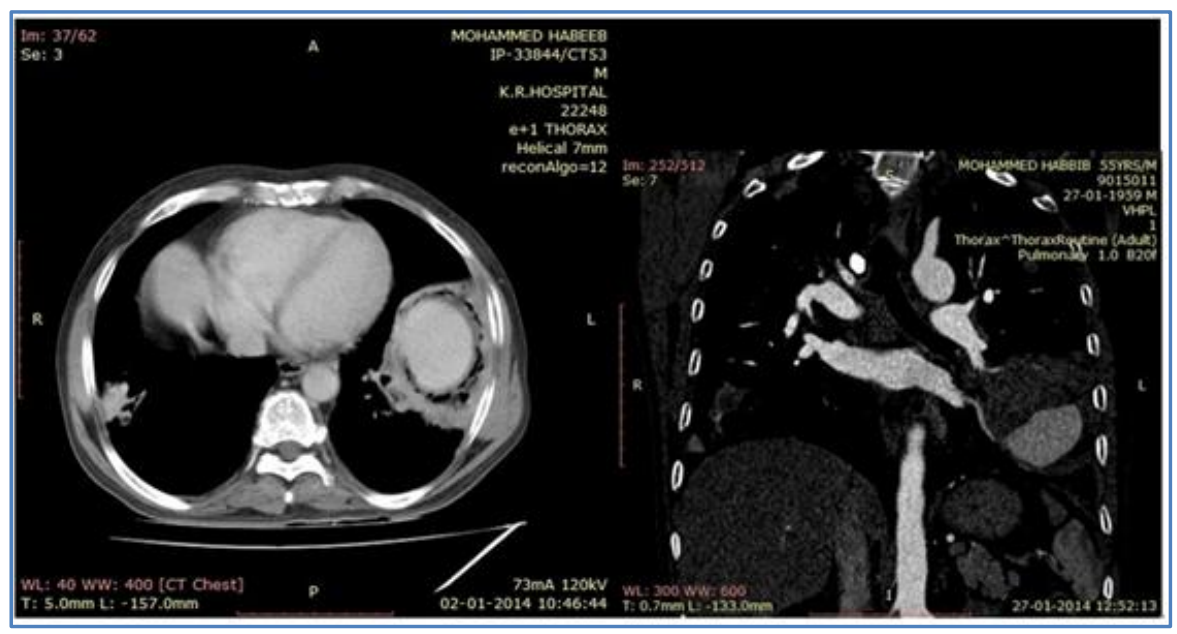

Figure 3: CECT scan showing well circumscribed left lower lobe radio enhancing intracavitary lesion suggestive of Rassmussen's aneurysm and MDCTA demonstrating a branch of left pulmonary artery feeding the lesion in the cavity. Note the increase in thrombus size.

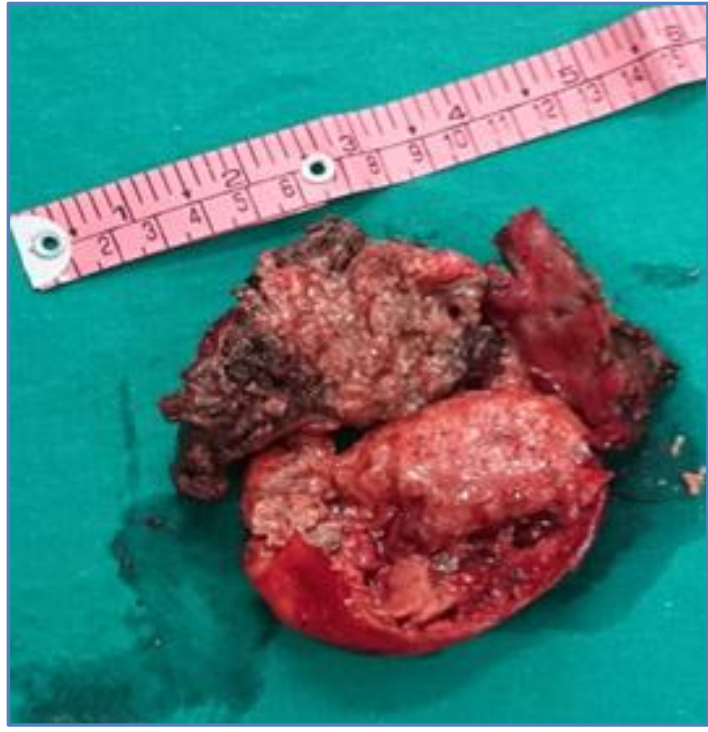

Figure 4: Resected pulmonary segments containing cavity, aneurysm and a large thrombus after wedge resection.

DISCUSSION: Pulmonary tuberculosis is common cause of hemoptysis, the incidence of hemoptysis in patients with pulmonary tuberculosis is 30 to $35 \%$, both in active disease and as a post tuberculosis sequelae. ${ }^{5}$ Hemoptysis may arise from numerous post tuberculosis sequalae and 
complications, it may occur due to 1) parenchymal lesions like cavity, aspergilloma. 2) airway lesions like bronchiectasis, broncholithiasis and 3) vascular lesions like bronchial arteritis and aneurysmal dilatation. ${ }^{190} \%$ of massive hemoptysis is due to involvement of bronchial circulation, pulmonary circulation is involved in $5 \%$ and in remaining 5\% it originates from the aorta i.e., from aortobronchial fistula, ruptured aortic aneurysm. ${ }^{6}$

Rasmussen's aneurysm is a rare complication of pulmonary tuberculosis, which arises from the wall of the cavity usually in the upper lobe with a prevalence rate of $5 \%{ }^{7}$. It was first described by Fritz Waldemer Rasmussen. It is a pseudo-aneurysm as histologically it does not encompass all the three layers of a muscular artery, and usually the endothelial lining is absent. There will be a focal dilatation of peripheral pulmonary artery in tuberculosis cavity. ${ }^{2}$

Inflammation and necrosis affect the wall of a TB cavity, which may become atrophic. Increased pressure can lead to weakening of walls, dilatation of blood vessels and formation Rasmussen's aneurysms. These blood vessels rupture due to increased pressure on strenuous work, exercise, coughing and thus can result in massive hemoptysis. ${ }^{4}$

Pulmonary artery pseudo-aneurysms (PAP) may be congenital or acquired.2, 8

\section{Congenital causes:}

- Valvular and post valvular stenosis

- Left to right shunt, patent ductus arteriosus, VSD, ASD.

- Patch aneurysms in tetralogy of fallot.

\section{Acquired causes:}

- Infections - Tuberculosis, lung abscess, mycotic PAP due to aspergilloma, mucormycosis and secondary to Sub acute bacterial endocarditis.

- Vasculitis - Behcets syndrome, Hughes-Stovin syndrome.

- Connective tissue abnormalities - Marfans syndrome, Ehlers Danlos syndrome.

- Neoplasms - primary tumors of pulmonary artery and pulmonary metastasis.

- Iatrogenic - due to malpositioned swanz ganz catheter, chest tube insertion, conventional angiography and surgery. ${ }^{2,8}$

Chest radiograph may show non-specific findings like focal lung consolidation, solitary pulmonary nodule or a mass. ${ }^{8}$ Contrast computed tomography shows a radioenhancing lesion, and can be recommended as a preliminary investigation to demonstrate the Rasmussen's aneurysm. ${ }^{6}$ Although conventional pulmonary angiography is a gold standard for diagnosis, MDCT angiography can confirm the diagnosis. ${ }^{9}$

Indications for radiological and surgical intervention is taken into consideration when major life threatening hemoptysis occur. ${ }^{1}$ pulmonary artery embolisation is considered as the first line of treatment in a patient with massive hemoptysis who is not fit for surgery. No randomized trials have compared results of interventional radiology with surgical resection. Surgical resection of the involved site allows the definitive recovery when the patient is operable, however it carries a $20 \%$ mortality. ${ }^{1,10}$

Embolisation, however is a emergency and temporary intervention. Surgical resection can be performed in surgically fit patient and when expertise for radiological intervention is not available as in our case. ${ }^{4}$ 
CONCLUSIONS: Rasmussen's aneurysm should be considered in the differential diagnosis of air crescent sign both in chest radiograph and plain CT. A contrast enhanced CT will always be of much help in finding intracavitary pulmonary artery pseudoaneurysms. Although conventional pulmonary angiography was gold standard for confirming Rasmussen's aneurysm CT pulmonary angiography can also do the same. First line of treatment is pulmonary artery embolisation in emergency and critically ill patient. Surgery is performed electively in surgically fit patient and is the definitive treatment.

\section{REFERENCES:}

1. Jayet PV, Denys A, Zellweger JP, Taillard CC, Maillard JO, Christen G et al. Succesful embolisation of Rasmussen's aneurysm for severe hemoptysis. Swiss med wkly: 2004; 134: 705-706.

2. Nguyen ET, Silva CI, Seely JM, Chong S, Lee KS, Miller NL. Pulmonary artery aneurysms and pseudoaneurysms in adults: Findings at CT and Radiography. AJR: 2007; Feb; 188:126-134.

3. Corr P. Pulmonary artery aneurysm as a cause of massive hemoptysis: diagnosis and management. Case reports in radiology: 2011; 141563.

4. Raghuram AR, Kumar S, Balamurugan K, Shankarasubramanian V, Babu SC, Krishnan R. Rasmussen's aneurysm - a brief report. IJTCVS:2005; 21 : 234-235.

5. D Behera. Complications of pulmonary tuberculosis. In: Sharma SK, Mohan A, editors. Tuberculosis: $2^{\text {nd }}$ Ed. New delhi. Jaypee; 2009: p518.

6. Peter $\mathrm{G}$, Roshan M. Hemoptysis in pulmonary tuberculosis-contrast tomography unmasking Rasmussen's aneurysm. EJM: 2011; 16; 208-210.

7. Shih SY, Tsai IC, Chang YT, Tsan YT, Hu SY. Fatal hemoptysis caused by ruptured Rasmussen's aneurysm. Thorax: 2010; 135616.

8. Lafita V, Borge MA, Demos TC. Pulmonary artery pseudoaneurysm: etiology, presentation, diagnosis and treatment. Semin Intervent Radiol: 2004; 24:119-123.

9. Khalil A, Parrot A, Nedelcu C, Fartoukh M, Marsault C, Carette MF. Severe hemoptysis of pulmonary artery origin: signs and role of multidetector row CT angiography. Chest: 2008; 133:212-219.

10. Keeling AN, Costello R, Lee MJ. Rasmussen's aneurysm: a forgotten entity?. Cardiovasc Intervent Radiol: 2008; 31:196-200. 


\section{CASE REPORT}

\section{AUTHORS:}

1. Virupaksha H. M.

2. Krishnaprasad

3. Kudri G. M.

4. Irfanahmed Makandar

\section{PARTICULARS OF CONTRIBUTORS:}

1. Professor and Head, Department of Pulmonary Medicine, Mysore Medical College \& Research Institute, Karnataka.

2. Assistant Professor, Department of Pulmonary Medicine, Mysore Medical College \& Research Institute, Karnataka.

3. Professor and HOD, Department of Cardio Thoracic Surgery, Mysore Medical College \& Research Institute, Karnataka.

4. Resident, Department of Pulmonary Medicine, Mysore Medical College \& Research Institute, Karnataka.

\section{NAME ADDRESS EMAIL ID OF THE} CORRESPONDING AUTHOR:

Dr. Virupaksha H. M, Professor and Head, Department of Pulmonary Medicine, Mysore Medical College \& Research Institute, Mysore-570015.

E-mail: dr.hmvirupaksha@gmail.com

Date of Submission: 30/05/2014.

Date of Peer Review: 31/05/2014.

Date of Acceptance: 31/05/2014.

Date of Publishing: 03/06/2014. 